\title{
Hybrid Capabilities and Industry 4.0 Job Demands in Recruiting Malaysian Graduates
}

\section{Ainol Mardhiyah Rahmat, Airil Haimi Mohd Adnan, Nor Marini Mohtar}

To Link this Article: http://dx.doi.org/10.6007/IJARBSS/v11-i1/9000

DOI:10.6007/IJARBSS/v11-i1/9000

Received: 03 November 2020, Revised: 01 December 2020, Accepted: 11 January 2021

Published Online: 27 January 2021

In-Text Citation: (Rahmat et al., 2021)

To Cite this Article: Rahmat, A. M., Adnan, A. H. M., \& Mohtar, N. M. (2021). Hybrid Capabilities and Industry 4.0 Job Demands in Recruiting Malaysian Graduates. International Journal of Academic Research in Business and Social Sciences, 11(1), 789-799.

Copyright: (c) 2021 The Author(s)

Published by Human Resource Management Academic Research Society (www.hrmars.com)

This article is published under the Creative Commons Attribution (CC BY 4.0) license. Anyone may reproduce, distribute, translate and create derivative works of this article (for both commercial and non-commercial purposes), subject to full attribution to the original publication and authors. The full terms of this license may be seen

at: $\underline{\text { http://creativecommons.org/licences/by/4.0/legalcode }}$

Vol. 11, No. 1, 2021, Pg. 789 - 799

Full Terms \& Conditions of access and use can be found at http://hrmars.com/index.php/pages/detail/publication-ethics 


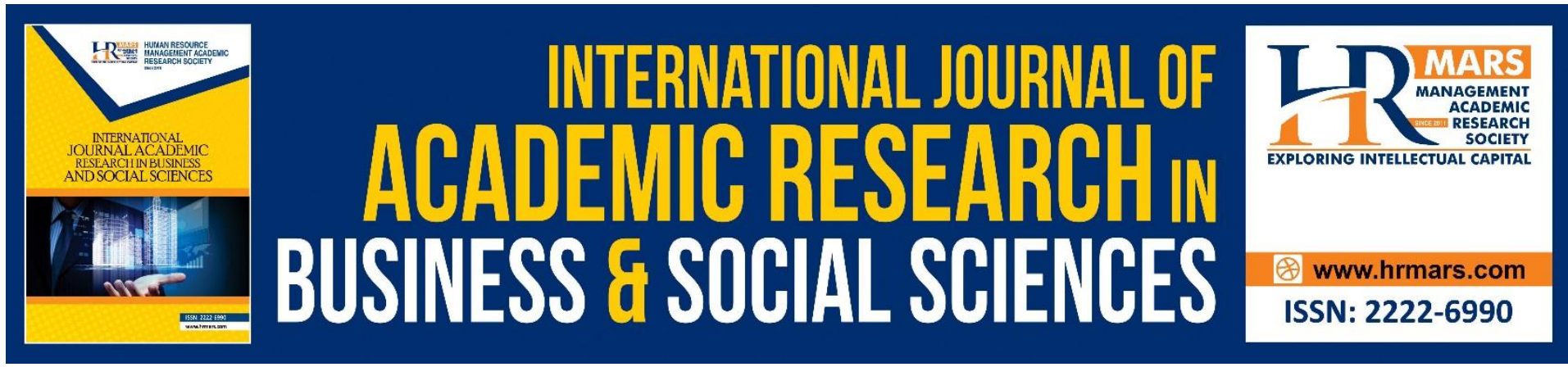

\title{
Hybrid Capabilities and Industry 4.0 Job Demands in Recruiting Malaysian Graduates
}

\author{
Ainol Mardhiyah Rahmat, Airil Haimi Mohd Adnan \\ Universiti Teknologi MARA Shah Alam, 40450 Selangor, Malaysia \\ Email: dhiyarahmat@gmail.com, airil384@uitm.edu.my \\ Nor Marini Mohtar \\ Universiti Teknologi MARA Perak Branch, 32610 Perak, Malaysia \\ Email:norma506@uitm.edu.my
}

\begin{abstract}
Industry 4.0 integrates digital transformation like big data and Internet of Things (IoT), making it difficult for Malaysian graduates to keep up with the rapidly changing job demands and competing with more experienced candidates. The truth is that youths nowadays face an increasingly robust and challenging working or labour environment. They need to keep up with the fast-paced working environment that is moving towards digital technology, with all the demands of employers requiring tons of skills to meet with current job demands. This research article aims to identify the capabilities that graduating students must possess to meet actual industry expectations for the Industry 4.0 era, and leading to the development of hybrid capabilities needed by employers as demanded during initial recruitment. The study reported in this article adopts a case study research approach, which is a qualitative method. Semi-structured interviews were conducted to gauge the experiences and collect opinions from employers, who are represented by professionals that hold power to make decisions in hiring new staff members. The results of this study show that there are significant differences in hybrid capabilities demanded by current employers. These comprise of technical, methodological, social, personal and digital processing capabilities. Not many studies have looked at the right mix of capabilities needed in the Industry 4.0 environment, especially on how the capabilities demanded may give impact on recruitment decisions.
\end{abstract}

Keywords: Industry 4.0, Non-Technical Capabilities, Technical Capabilities, Hybrid Capabilities, Recruitment Decision

\section{Introduction}

The first industrial revolution focused on machines followed by the second industrial revolution that honed on electrification. In contrast, the third industrial revolution covers digital transformations that later improved through the implementation of the fourth industrial revolution or Industry 4.0. Industry 4.0 integrates digital transformations through the use of Cyber-Physical Systems (CPS) that create a new business with and innovative products that are more customer-oriented. Industry 4.0 is not only for the manufacturing 
industry but also considers the overall digital transformation and integration within other business organization (Catal \& Tekinerdogan, 2019).

Millions of young people around the world are unemployed or underemployed, while employers have positions that cannot be filled. As of 2018, 1.8 billion youths all over the world, with an age range of between 15 to 29 show the highest population increase that will give impacts on employment (Deloitte Global Business Coalition For Education, 2018). Unemployment issues among graduates in Malaysia have garnered attention in the past few years due to high production of graduates' from numerous higher education institutions including public and private universities, higher education colleges, tertiary polytechnics, and vocational colleges. The Graduate Tracer Survey Report 2018, published by the Ministry of Education Malaysia in 2019, found that only $58.6 \%$ of the respondents in the survey are employed (Ministry of Education, 2019). Based on the latest evidence reported by the former Minister of Education, Dr Maszlee Malik, the number of unemployed graduates rose to $59.9 \%$, which is equal to 30,765 graduates of 51,365 graduates who completed their studies each year.

The current economic environment and the rapid transformation of digital technology increasingly pressure young people to compete in the employment market. Technological disruptions caused by new categories of jobs and occupations also demand new sets of capabilities that will be needed in both current and new professions (Hecklau et al., 2016). The main problem has often been a debate is the graduates' inability to possessed specific capabilities needed by employers' comprising both technical and non-technical skills. Furthermore, New Straits Times highlighted, graduates' inability to portray a diverse mix of skills is also one of the reasons the employers prefer to hire experienced candidates that already possess multiple capabilities (Kaur, 2017). The change of job demands and the shift towards digital technology and automation is also one of the primary factors that cause job losses that require a new position to be fill related to technical and non-technical capabilities (The Star, 2020). Looking into the current employment trend with a diverse mix of capabilities demanded, the actual skills of the graduates might raise a critical question, as to whether local graduates are fully equipped with all the skills required.

Finch, Peacock, Levallet, and Foster (2015) suggest that there is a need to explore how university students may succeed during the recruitment and selection process. Therefore, this present research will explore the views of employers and their experiences in hiring fresh graduates, specifically in terms of capabilities portrayed during the recruitment process. However, before rectifying the issues that employers face during recruitment and selection, it is crucial to investigate the main issues of unemployment of graduates, specifically in terms of lack of capabilities. From identification of the skills demanded, this will drive the next questions on employers' decision-making in recruitment (Finch et al., 2015).

\section{Literature Review}

This section further develops the points raised in the introduction chapter, which provides an overview of this research. This chapter entails the broader background of the concept of capabilities required in the Industry 4.0 setting and provides an introduction of hybrid capabilities needed in this Industry 4.0 era. The identification of capabilities demanded in Industry 4.0 is a benchmark whether there are changes in capabilities demanded from the previous industry to the current Industry 4.0. 


\section{The demands of Capabilities in Industry 4.0, an Employers' perspective}

The increased demands for capabilities is a response to change in technology, which has brought about the globalization of markets, international competition, the drive for productivity growth, sector reforms and a change in output demands (Pitan, 2017). These changes are so fundamental that prospective graduate employees need to develop a broad range of generic capabilities to cope with the demands of their jobs (Pitan, 2017). The Resource-Based View theory developed by Barney (1991) mentioned that organizations might achieve competitive advantage by developing both tangible and intangible resources that rare, valuable, and hard to imitate or replace. In creating an organization's competitive advantage, an organization needs a set of dynamic capabilities to create values. However, an individual must achieve a competitive advantage through the development of new capabilities by possessing the right hybrid capabilities to compete in the job market.

There is a broad topic of graduate capabilities conducted considering employers' perspectives (Ismail \& Hassan, 2019; Lee, 2019; Low, Gao, \& Ng, 2019; Pitan, 2017; Verma et al., 2018). Earlier literature revealed that many employers were dissatisfied with the capabilities graduates demonstrated and therefore led to employers' reluctance in hiring fresh graduates (Verma et al., 2018). As technology is evolving, the way of performing a job requires a diverse mix of capabilities to integrate human-machine interaction. Therefore, the graduates must be fully equipped with both technical and non-technical capabilities to 'stand out' in the employment market. Non-technical capabilities are associated with personality, attitude, and behaviour rather than formal or technical knowledge (Teng, Ma, Pahlevansharif, \& Turner, 2019). Previous research defines non-technical capabilities as an ability related to social and emotional intelligence (Jameson, Carthy, McGuinness, \& McSweeney, 2016). There are extensive studies on the importance of non-technical capabilities from the employer's perspective (Almutairi \& Hasanat, 2018; Teng et al., 2019; Vooren, Haelermans et al., 2019).

With a different long list of capabilities demanded using different terms, many authors have attempted to group the capabilities according to relevant categories for simplification and clarity. For instance, Hecklau et al., (2016), identified a set of capabilities according to four categories which are, Technical Capabilities, Methodological Capabilities, Social Competencies, and Personal Competencies. However, the researchers keep a very general viewpoint on the graduates' attributes, lacking further information on how the categorization of capabilities may affect the employers' decision to hire. Furthermore, the researchers integrate the capabilities demanded across various sectors. Therefore, this research will explore the needs of integrating capabilities by narrowing to the manufacturing and services sectors.

\section{Hybrid Capabilities for the Future of Jobs}

Hybrid capabilities are a combination of technical and non-technical capabilities that require employees to have a set of technical capabilities to complement non-technical capabilities. In the Wall Street Journal, employment experts mentioned that the future of jobs requires the employee to tap both technical and non-technical capabilities to perform hybrid jobs (Weber, 2019). Depending on the job and business, what is called hybrid jobs can differ. For instance, the employer is looking for administrative personnel who can welcome guests, answer phones and organize files. At the same time, also possess a set of capabilities that includes social media, website updates, presentation material design and manipulation of table sheets and database programs (Weber, 2019) 
The new job requires the employee to perform multi-task jobs that require them to possess a set of hybrid capabilities relevant to the nature of the job. A report from Burning Glass Technologies identified a huge hybrid trend across the United States demands capabilities that combine necessary programming capabilities along with abilities in design, data analysis, and marketing (Burning Glass Technologies, 2019). This statement shows that change of jobs with the demands for hybrid capabilities will give a significant impact and pose more enormous challenges for employees, students, government, current employees as well as educators to keep up with changing capabilities requirements.

\section{Methodology}

This research is a qualitative research (Creswell, Hanson, Clark Plano, \& Morales, 2007). Qualitative research contributes to a greater understanding in exploring underlying values, beliefs, and assumptions (Yauch \& Steudel, 2003). Qualitative approaches offer more flexibility in collecting data through interviews, which allow greater spontaneity during the interaction between the researcher and participant since qualitative methods mostly ask 'open-ended' questions that probe participants' opinions (Mack, Woodsong, Macqueen, Guest \& Namey, 2005). This research aims to explore employers' preferences on the capabilities of graduates at public universities. This research elicits the experiences and opinions of industry experts who are actively involved in decision making to hire candidates in their respective organizations.

This research employs face-to-face interviews with a semi-structured interview question design. The rationale of having a face-to-face interview is to capture immediate responses to opinions and to track the non-verbal cues while expressing an opinion that will help in generating positive findings. In-depth interviewing is a technique designed to generate a broader perspective related to the research topic. The participant is typically someone who has experience and expertise in the areas of research that we explore. In-depth interviews help the researcher to gain greater insight into understanding people's opinions and experiences.

Audio recording and video data were collected and transcribed. Due to COVID-19, the researchers had two options whether to conduct face-to-face interviews at the premises or through video conferencing using Zoom or Google Meet, depending on availability and flexibility. If the organization chooses to have a face-to-face interview at their premises, audio recording and note-taking became an option. We also used a digital audio recorder that provides precise audio and digital pitch control. Another tool is text-to-speech applications provided by Google, which allows the researchers to listen to the recorded video or audio, and the applications will automatically transcribe the speech in textual format. Google Docs comes handy during this text-to-speech process. Reading the data require our capabilities to analyze the data critically. Therefore, we still need to use our capabilities in identifying the meanings of the data, which cannot be performed using technology.

\section{Results}

\section{Identifying Capabilities in the Industry 4.0}

All the participants reached a universal consensus that having hybrid skills are essential for Industry 4.0 in the manufacturing and service sector. This research is consistent with Weber (2019) that it is equally important to have a mix of capabilities to secure employment. 
Table 1: Summary of Capabilities Demanded by the Employer

\begin{tabular}{|c|c|c|c|c|c|c|}
\hline \multirow{2}{*}{ DOMAIN } & \multirow{2}{*}{ ELEMENTS } & \multicolumn{5}{|c|}{ PARTICIPANTS } \\
\hline & & PARTICIPANT \#1 & PARTICIPANT \#2 & PARTICIPANT \#3 & PARTICIPANT \#4 & PARTICIPANT \#5 \\
\hline \multirow{4}{*}{ TECHNICAL CAPABILITIES } & Programming & $\mathrm{x}$ & I & $\mathrm{x}$ & $\mathrm{x}$ & $\mathrm{x}$ \\
\hline & Understanding IT Security & $\mathrm{x}$ & $\mathrm{x}$ & $\mathrm{x}$ & $\mathrm{x}$ & 1 \\
\hline & Process Understanding & / & / & / & $\mathrm{x}$ & I \\
\hline & Troubleshooting & I & $\mathrm{x}$ & I & $x$ & $\mathrm{x}$ \\
\hline \multirow{5}{*}{ METHODOLOGICAL CAPABILITIES } & Creative Thinking & I & / & / & I & $\mathrm{x}$ \\
\hline & Critical Thinking & I & $x$ & / & I & I \\
\hline & Complex Problem Solving & I & I & I & I & I \\
\hline & Aalytical Skill & $x$ & $x$ & I & I & I \\
\hline & Research Skill & $\mathrm{x}$ & $\mathrm{x}$ & $\mathrm{x}$ & $\mathrm{x}$ & $x$ \\
\hline \multirow{4}{*}{ SOCIAL CAPABILITIES } & Communication Skills & I & l & I & I & I \\
\hline & Networking Skills & I & $x$ & $x$ & $x$ & $x$ \\
\hline & Teamwork & I & I & I & I & $x$ \\
\hline & Leadership Skill & $\mathrm{x}$ & $\mathrm{x}$ & $\mathrm{x}$ & $\mathrm{x}$ & $\mathrm{x}$ \\
\hline \multirow{4}{*}{ PERSONAL CAPABILITIES } & Emotional Intelligence & I & $x$ & / & I & I \\
\hline & Cognitive Flexibility & I & $x$ & / & I & I \\
\hline & Motivation to Learn & $x$ & I & I & $x$ & I \\
\hline & Compliance & $x$ & I & I & $\mathrm{x}$ & I \\
\hline \multirow{3}{*}{ DIGITAL PROCESSING CAPABILITIES } & Information Media & I & I & I & I & I \\
\hline & Digital Literacy & / & / & I & I & / \\
\hline & Data Analytics & $x$ & 1 & 1 & $\mathrm{x}$ & 1 \\
\hline
\end{tabular}

"The graduates must have non-technical and technical capabilities. Graduates should have a basic understanding of technical skills and utilize non-technical capabilities to interact with people internally and externally" (Participant 5). A few interviewees have a different point of views on capabilities demanded. Table I summarises the results of interview data relating to capabilities demanded by the employer.

Technical Capabilities. Earlier research mentioned technical capabilities are highly needed in specific jobs, based on occupational clusters of employment fields and advanced levels of technical skills across all industries and jobs from entry-level to the highest level of management (Bhaerman \& Spill, 1988). Participant 2 stated, "The graduates do not need to have programming skills. However, they need to have a basic understanding of how the programme works. We value creative thinker and at the same time, can work independently and brave enough to ask questions". Contrary to Participant 3 opinions on skills demanded, Participant 3 are looking forward to hiring graduates that possess excellent technical capabilities to perform a technical task. Participant 3 quoted: "We want people who already know how to perform the technical job. However, for the non-technical position such as an admin assistant, that person must have basic knowledge on understanding analytical data".

Methodological Capabilities. Methodological capabilities are related to generic skills that focus on capabilities for general problem solving and decision making (Hecklau et al., 2016). Employers aspire to hire candidates that own creative thinking capabilities. Research studies found that employers are dissatisfied with the student's ability to think creatively (Akman \& Turhan, 2018; Aluko, 2014; Hollister et al., 2017). This statement is consistent with most of the interviewee. For example, Participant 3 quoted: "Creative thinking is important. We need people that can interpret data and able to represent it in an original format. Interestingly, Participant 4 also express his agreement for graduating students to have excellent problem-solving skills. Participant 4 contended: "we are in a service industry, the ground service team needs to be able to solve the problem and make decisions promptly especially when dealing with passengers from a foreign country that has issues to follow the SOP".

Social Capabilities. All of the participant's opinions seem to be fair and closely similar with other participants, due to the fact the interviewee actively involved in the hiring process in the organization. Employers place great importance on communication skills and teamwork 
skills, as it leads people to work closely together to perform a task. Participant 1 quoted on the teamwork skills: "You may be the best person, but if you make your team quit and you can't make them happy, then you are not fit with our organization". The statement highlighted by Participant 1 is proof that the organization value people who have good teamwork and prioritize in a good working environment. Interestingly, Participant 3 also emphasized the importance of having good teamwork skill. Participant 3 observed: We need the graduates to be able to work with others since we are operating for 24/7; the pressure is there, so we need people who have excellent teamwork skills, to be flexible and willing to accept responsibility when we needed".

Personal Capabilities. Personal competencies are essential for employers in determining whether the applicants are 'fit' with the job and organization culture and values (Gardner et al., 2012; Supjarerndee, Temtanapat, \& Phalavonk, 2002). Personal capabilities deem to be the most valuable skills that employers seek in hiring fresh graduates. The personality of the candidates portray during a job interview plays a significant role in hiring decision. According to Participant 5, "It is understandable for the graduates for not having all the skills mentioned, but we need people who are flexible, willing to accept new responsibility. Some of the graduates feel reluctant to accept job responsibility that is not within their job scope". Also, Participant 1 and Participant 4 shared the same opinions on cognitive flexibility and willingness to learn which they need the graduates to be able to work independently with minimum supervision.

Digital Processing Capabilities. Digital processing involves the use of internet connection as a getaway of discovering new knowledge through the extraction of big data where the use of digital media, information processing, and social networks are the necessary capabilities required by the graduates that frequently asked during a job interview (Lee, 2018). Participant 3 justified: "We need digital literate people to control business operation using our TRAX system. We need the employee to learn the system by themselves in a quick time as we are highly relying on the TRAX system to control the flight operations". However, Participant 1 noted that the graduates do not need to have digital processing capabilities, depending on the nature of work.

\section{Hybrid Capabilities in the Industry 4.0 Environment}

There is a consensus on the importance of having hybrid capabilities in the recruitment of young people. In the interview, we asked the participants on the hybrid capabilities they need. According to Participant 1, "We look for people who have specific skills, according to the functions. For example, for Business Development, we do not need them to have big data analytic skill. However, we need them to understand the numbers so that they can create good marketing strategies as well as creative thinking to create a marketing campaign". Based on the statement, we found that Participant 1 put great attention on Methodological Capabilities and Digital Processing Capabilities.

Participant 3 shared his opinion on the importance of having creative thinking skills to perform the task. Participant 3 observed: Depending on the department, as for the Ground Team, we need people who have a right combination of communication skills, digital skills and complex problem-solving skills to handle passengers with unique behaviour. For example, the airline service staff must have excellent communication skills, especially in the English language, to communicate with international passengers. The staff needs to solve the problem promptly relating to passengers reluctance to follow SOP, especially when it comes 
to dangerous goods and baggage weight". It seems that Participant 3 will look into a mix of Methodological, Social and Digital Processing Capabilities in hiring young candidates.

Contrary to Participant 3 opinions, he contended: "We will look into their willingness to work in long hours and under pressure since we operate $24 / 7^{\prime \prime}$. We followed up questions on the qualities that the candidates are looking for in the graduates. Participant 3 explained: "We have a lot of experience candidate, to compete with experienced people; the graduates must know how to sell themselves." We then further the questions on how the candidates sell themselves, Participant 3 declared: 'They need to do more research on the organization and the job scope and proof to us that they are the right candidate, and able to adapt with the challenging working environment. A fast learner, I may say. We also need a candidate that is a team player, with a good attitude and willingness to explore, solve the problem and make decisions". The participant 3 mentioned quite a lengthy statement on capabilities demanded. We followed up on the top hybrid capabilities needed. Participant 3 concluded that Methodological, Personal and Technical Capabilities are the demanded skills that he thinks the graduates must-have.

\section{Employers' Decision to Hire Fresh Graduates}

In this research, we examined how hybrid capabilities demanded may drive employers to decide whether to hire graduates or not. Consistent with the earlier researches, Participant 1 assess the capabilities during the interview session. According to Participant 1, "We will assess candidate's capabilities through assessment provide real situation and see how they can solve the problem, if they can provide solutions then we will consider hiring candidates. We will assess the Curriculum Vitae, but do not focus on academic qualifications, because we believe all candidates must be given a chance, we are not looking into their background education. However, we will still look into the subjects to match with the job offered'.

Participant 2 highlighted that he would look into the Curriculum Vitae, screening candidates based on qualifications. Participant 2 contented: We will look into his CV, looking into their qualifications and educational background as well as checking if there is any grammatical error and misspelling in their CV'. We then followed up to questions whether they take into account the GPA that the students have. Participant 2 responded: "We receive hundreds of applications, it is not necessary to have good GPA, but we are filtering them to fasten the process of screening candidates for a job interview". Participant 2 also declared: "For a job interview, we will conduct an online assessment to test their skills. For example, for a system developer, we will conduct a coding test. During the job interview, there are 5 people in the room including me, the CEO, Human Resource Manager, Manager in the department and 2 random people (the staff), asking opinion from different roles. When we want to select people, it is not really about the job, the attitude of that person, whether he or she can fit in the organization and teamwork is important. You may be the best person, but if you make your team quit and you can't make them happy, then you are not fit with our organization."

Contrary to participant 4 observed: We will check their Curriculum Vitae, we will look into their educational background, and Participant 4 Hiring process depends on HOD, request for additional staff to CEO. If the CEO agrees then we will conduct a walk-in-interview and blast the information through our social media platform such as Facebook. We have 4 stages of interview First stage, is a physical test, which we measure a candidate's physical requirement, including the $\mathrm{BMI}$. The second stage is an English test. The candidates are required to have the maximum score during this stage. Stage 3 involves a group discussion on 
random topics to assess a candidate's capabilities in communication through the expression of ideas. The last stage will be health and medical check-up. The candidates would not proceed to the next stage if they failed at the first stage of the assessment". Interestingly, Participant 3 mentioned that "We will only review their Curriculum Vitae once they passed all the interview stages".

\section{Conclusion}

Despite the disruption of technology that Industry 4.0 brings and how the disruption gives impacts to changes in job demands, we need to face the challenges and be prepared for the challenges. The graduates need to recognize the actual capabilities highly demanded before they graduates and find possible solutions to gain as many opportunities to upskilling and benefited from the disruption of technologies. The disruption brought by Industry 4.0 were explored through employer's perceptions.

Our empirical findings indicate that, firstly, graduating students in Malaysia lack social, methodological and personal capabilities and feel reluctant to learn new capabilities related to digital technology. Secondly, expect the future graduates to have nearly all combination of hybrid capabilities; however, they will also consider future graduates who have basic knowledge of technical and digital processing capabilities. Thirdly, employers express their strong dissatisfactions on social and personal capabilities, where the fresh graduates do not portray the right attitudes and fail to express their interests in the jobs they applied. Poor communication skills is also one of the significant issues that need attention.

This research examined the hybrid capabilities demanded by employers in the Industry 4.0 environment, focusing on the manufacturing and service industry. However, methodologically, our participants are not large; it has several limitations. For instance, this study is only focused on the manufacturing and services industry. Since Industry 4.0 implementation is relatively new in Malaysia, this research only managed to focus on businesses that are currently involved in Industry 4.0. In addition, since different job positions have distinct sets of hybrid capabilities need, the results may be unique, depending on job roles and responsibilities. For example, a project engineer may need technical capabilities and differ from a human resource personnel since different roles 'see' the needs of specific capabilities from a different point of view. In this sense, the interests and concerns of an individual may affect the overall results. Further research covering specific job roles would be useful, in future.

\section{Acknowledgement}

The corresponding author would like to thank all the participants involved in the interview during her fieldwork. The corresponding author also acknowledges the support of her main supervisor, Madam Marini binti Mohtar from Universiti Teknologi MARA, Seri Iskandar Campus in guiding the whole research project. Special thanks to the Fundamental Research Grant Scheme (FRGS) from the government of Malaysia for granting financial assistance to this research project.

\section{Corresponding Author}

Ainol Mardhiyah Rahmat

Universiti Teknologi MARA Shah Alam, 40450 Selangor, Malaysia

Email: dhiyarahmat@gmail.com 


\section{References}

\section{Journal Article}

Akman, I., \& Turhan, C. (2018). Investigation of employers' performance expectations for new IT graduates in individual and team work settings for software development. Information Technology and People, 31(1), 199-214. https://doi.org/10.1108/ITP-01-2017-0020

Almutairi, M. M., \& Hasanat, M. H. A. (2018). Predicting the suitability of IS students' skills for the recruitment in Saudi Arabian industry. 21st Saudi Computer Society National Computer Conference, NCC 2018, 1-6. https://doi.org/10.1109/NCG.2018.8593016

Aluko, Y. (2014). Employers' perceptions of the employability skills of new graduates in nigeria. Journal of Educational Review, 7(4), 12.

Bhaerman, R., \& Spill, R. (1988). How Can They Be Taught ? Journal of Career Development, 15(I), 41-52.

Burning Glass Technologies. (2019). The Hybrid Job Economy. (January). Retrieved from https://www.burning-glass.com/wp-content/uploads/hybrid_jobs_2019_final.pdf

Catal, C., \& Tekinerdogan, B. (2019). Aligning Education for the Life Sciences Domain to Support Digitalization and Industry 4.0. Procedia Computer Science, 158, 99-106. https://doi.org/10.1016/j.procs.2019.09.032

Creswell, J. W., Hanson, W. E., Clark Plano, V. L., \& Morales, A. (2007). Qualitative Research Designs: Selection and Implementation. The Counseling Psychologist, 35(2), 236-264. https://doi.org/10.1177/0011000006287390

Dasar, B. P. dan P. (2018). Pengesanan 2018. Kementerian Pendidikan Malaysia Putrajaya, 101.

Deloitte Global Business Coalition For Education. (2018). Preparing tomorrow's workforce for the Fourth Industrial Revolution / Deloitte / About. 1-58. Retrieved from https://www2.deloitte.com/global/en/pages/about-deloitte/articles/gx-preparingtomorrow-workforce-for-the-fourth-industrialrevolution.html?id=gx:2sm:3tw:4GBCed2018::6abt:20180919220600:SociallmpactReport\&utm_source=tw\&utm_campaign=GBCed2018\&utm_content=

Finch, D. J., Peacock, M., Levallet, N., \& Foster, W. (2015). A dynamic capabilities view of employability. Education + Training, 58(1), 61-81. https://doi.org/10.1108/et-02-20150013

Gardner, W. L., Reithel, B. J., Cogliser, C. C., Walumbwa, F. O., \& Foley, R. T. (2012). Matching Personality and Organizational Culture: Effects of Recruitment Strategy and the FiveFactor Model on Subjective Person-Organization Fit. Management Communication Quarterly, 26(4), 585-622. https://doi.org/10.1177/0893318912450663

Hecklau, F., Galeitzke, M., Flachs, S., \& Kohl, H. (2016). Holistic Approach for Human Resource Management in Industry 4.0. Procedia CIRP, 54, 1-6. https://doi.org/10.1016/j.procir.2016.05.102

Hollister, J. M., Spears, L. I., Mardis, M. A., Lee, J., McClure, C. R., \& Liebman, E. (2017). Employers' perspectives on new information technology technicians' employability in North Florida. Education and Training, 59(9), 929-945. https://doi.org/10.1108/ET-022017-0019

Ismail, A. A., \& Hassan, R. (2019). Technical competencies in digital technology towards industrial revolution 4.0. Journal of Technical Education and Training, 11(3), 55-62. https://doi.org/10.30880/jtet.2019.11.03.008

Jameson, A., Carthy, A., McGuinness, C., \& McSweeney, F. (2016). Emotional Intelligence and Graduates - Employers' Perspectives. Procedia - Social and Behavioral Sciences, 
228(June), 515-522. https://doi.org/10.1016/j.sbspro.2016.07.079

Lee, M. F. (2019). Digital Skills Measurement: A Study on the Malaysian Youth. 2018 IEEE Conference on E-Learning, e-Management and e-Services, IC3e 2018, 52-55. https://doi.org/10.1109/IC3e.2018.8632628

Low, S. P., Gao, S., \& Ng, E. W. L. (2019). Future-ready project and facility management graduates in Singapore for industry 4.0: Transforming mindsets and competencies. Engineering, Construction and Architectural Management. https://doi.org/10.1108/ECAM-08-2018-0322 Methods : Methods : (n.d.).

Pitan, O. S. (2017). Graduate employees' generic skills and training needs. Higher Education, Skills and Work-Based Learning, 7(3), 290-303. https://doi.org/10.1108/HESWBL-042017-0026

Supjarerndee, S., Temtanapat, Y., \& Phalavonk, U. (2002). Recruitment filtering with personality-job fit model. Proceedings - International Conference on Information Technology: Coding and Computing, ITCC 2002, 14(3), 46-51. https://doi.org/10.1109/ITCC.2002.1000358

Teng, W., Ma, C., Pahlevansharif, S., \& Turner, J. J. (2019). Graduate readiness for the employment market of the 4th industrial revolution: The development of soft employability skills. Education and Training, 61(5), 590-604. https://doi.org/10.1108/ET07-2018-0154

Verma, P., Nankervis, A., Priyono, S., Moh'D Saleh, N., Connell, J., \& Burgess, J. (2018). Graduate work-readiness challenges in the Asia-Pacific region and the role of HRM. Equality, Diversity and Inclusion, 37(2), 121-137. https://doi.org/10.1108/EDI-01-20170015

Vooren, M., Haelermans, C., Groot, W., \& Van den Brink, M. H. (2019). Employers' preferences for IT-retrainees: evidence from a discrete choice experiment. International Journal of Manpower, 40(7), 1273-1287. https://doi.org/10.1108/IJM-01-2019-0001

Weber, L. (2019). Wall Street Journal. Retrieved from The Wall Street Journal: https://www.wsj.com/articles/the-hybrid-skills-that-tomorrows-jobs-will-require11547994266

Yauch, C. A., \& Steudel, H. J. (2003). Complementary Use of Qualitative and Quantitative Cultural Assessment Methods. Organizational Research Methods, 6(4), 465-481. https://doi.org/10.1177/1094428103257362

\section{Online Newspaper}

Kaur, B. (2017). New Straits Times. Retrieved from New Straits Times: https://www.nst.com.my/news/nation/2017/10/289944/employers-preferexperienced-workers-fresh-graduates-jobsmalaysia 